\title{
Real-Time In-Pile Acoustic Measurement Infrastructure at the Advanced Test Reactor
}

Vivek Agarwal, James A. Smith

February 2017

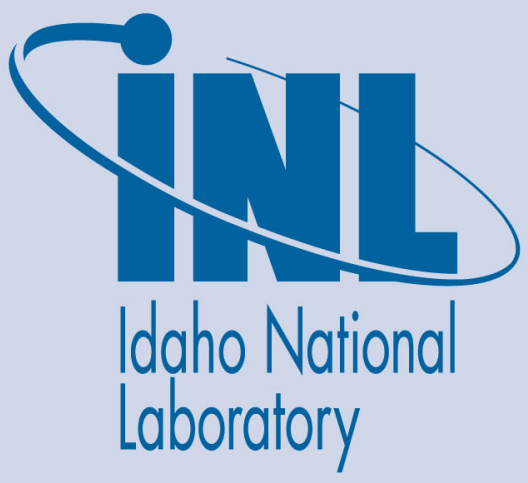

The INL is a U.S. Department of Energy National Laboratory operated by Battelle Energy Alliance 


\section{Real-Time In-Pile Acoustic Measurement Infrastructure at the Advanced Test Reactor}

Vivek Agarwal, James A. Smith

February 2017

Idaho National Laboratory Idaho Falls, Idaho 83415

http://www.inl.gov

Prepared for the U.S. Department of Energy Office of Nuclear Energy Under DOE Idaho Operations Office

Contract DE-AC07-05ID14517 
Revised Submission Type: Nuclear Technology Letters

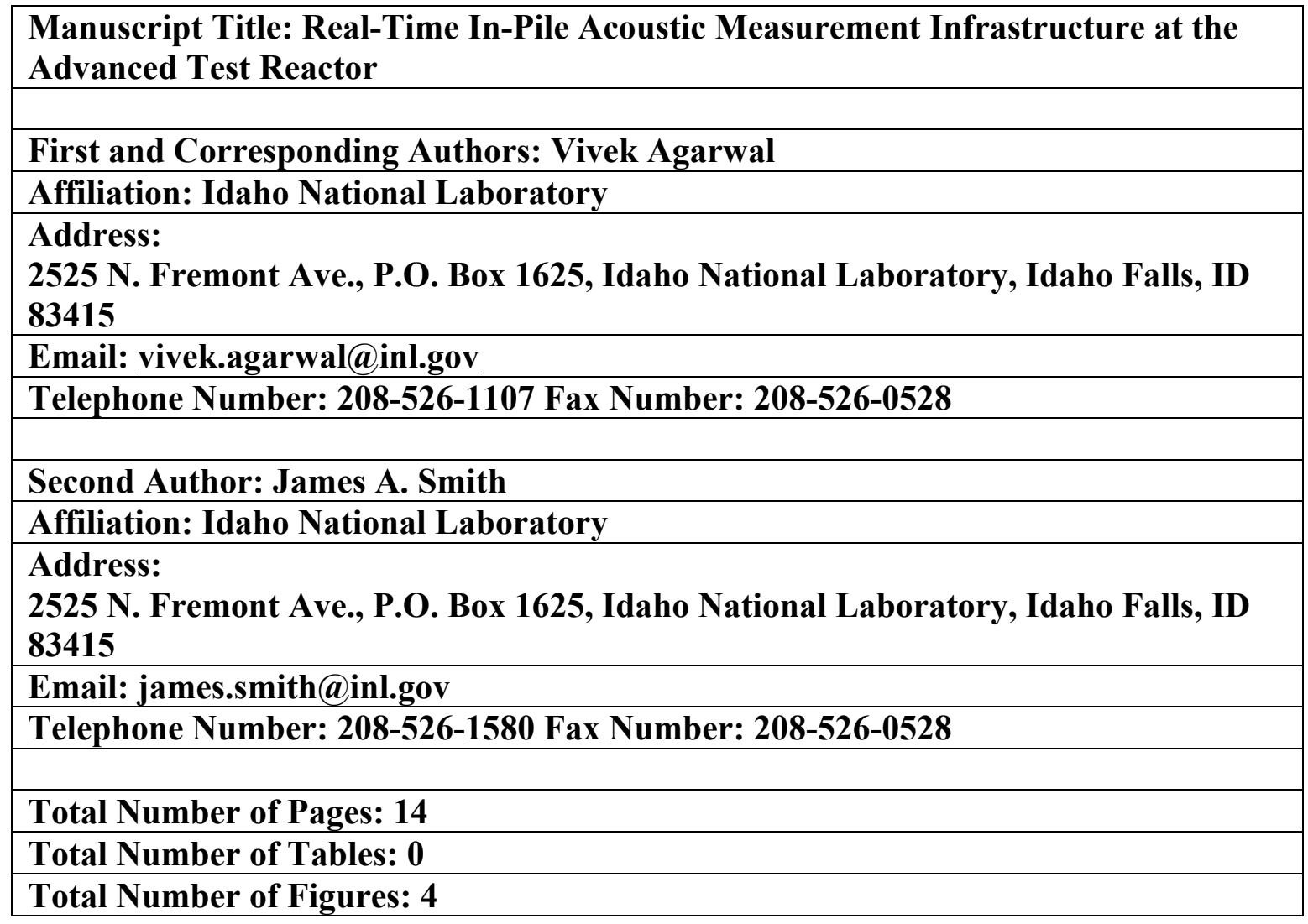


Abstract: The core of any nuclear reactor presents a particularly harsh environment for sensors and instrumentations. The reactor core also imposes challenging constraints on signal transmission from inside the reactor core to outside of the reactor vessel. In this paper, an acoustic measurement infrastructure installed at the Advanced Test Reactor (ATR), located at Idaho National Laboratory, is presented. The measurement infrastructure consists of ATR in-pile structural components, coolant, acoustic receivers, primary coolant pumps, a data-acquisition system, and signal processing algorithms. Intrinsic and cyclic acoustic signals generated by the operation of the primary coolant pumps are collected and processed. The characteristics of the intrinsic signal can indicate the process state of the ATR (such as reactor startup, reactor criticality, reactor attaining maximum power, and reactor shutdown) during operation (i.e., real-time measurement).

\section{Introduction}

A salient grand challenge for a number of U.S. Department of Energy programs under the Office of Nuclear Energy is to enhance the fundamental understanding of reactor fuel and material behavior subjected to intense irradiation. Traditionally, radiation-hardened sensors and their associated signal-conditioning electronics are used to study key parameters of fuel and materials inside the reactor core before and after irradiation [1]. The limitations of traditional approaches include (1) the inability to provide non-intrusive real-time measurement, (2) the requirement of at least two wires to power and communicate information from inside to outside of the reactor vessel, and (3) degradation of the performance of sensors and their associated instrumentations/electronics over time and the associated impact on measurement accuracy and model predictions [2]. 
Despite the hostile environment of a nuclear reactor for sensing and electrical communication, the reactor core is amenable to acoustic telemetry. A research and development effort on acoustic-based sensors, such as thermoacoustic sensors $[3,4]$ at Idaho National Laboratory and vibro-acoustic [5] sensors, has enabled real-time and wireless (i.e., transmission of sound via fluids, mechanical structures, pipes, and conduits) in-pile measurement of key parameters such as temperature, flux, fueldimension changes, and fission gases. This motivated the development and installation of the Acoustic Measurement Infrastructure (AMI) presented in this paper. AMI is installed at the Advanced Test Reactor (ATR), one of the Nuclear Science User Facilities [6].

The fundamental premise behind the AMI is the belief that listening to a reactor's intrinsic acoustic sources and extrinsic acoustically telemetered sensors will allow for efficient real-time processing (process data in time to acquire new data continuously) and nonintrusive characterization of a reactor under normal operation and transient testing. Advanced signal processing algorithms are used to extract in-pile information buried in a noisy environment and to identify an acoustic signature that characterizes reactor process states. The acoustic signature of a reactor under different operating conditions presents an opportunity to (1) identify quiescent frequency ranges that would aid in the design of an acoustically telemetered sensor carrier frequency (2) enhance/tune the acoustically telemetered sensor design prior to fabrication and installation inside the reactor core. As part of sensor design, it is important to recognize changes in the frequency spectrum as part of reactor operational changes; (3) understand and characterize the salient measurement parameters of an acoustically telemetered sensor signal (i.e., frequency, amplitude, and phase); and (4) provide early detection of pending sensor failure or 
degradation. The applications to structural health monitoring are possible with proper signal processing/classification techniques with minimal impact on reactor safety or control systems. For example, in the ATR Full Size In-Flux Trap Position-6 MKII experiment [7], flow-induced vibration caused a non-fueled component of the first fuel plate frame assembly to separate from the rail sides inside the reactor. With the vibrational baseline and active monitoring of the reactor, it would have been possible to identify and prevent this type component failure during an experiment.

The innovation of AMI can be extended to collect information on other phenomena, such as fuel motion, individual fuel rod vibration, loose parts, thermal expansion, and flow blockage, that occur inside an operating nuclear reactor. This paper focuses on intrinsically telemetered data provided by the AMI installation at the ATR and initial interpretations that will impact acoustically telemetered sensors and instrumentation for the nuclear industry or for industrial applications with challenging operating conditions.

\section{Acoustic Measurement Infrastructure}

The current implementation of AMI includes ATR in-pile structural components, coolant, acoustic receivers, primary coolant pumps (PCPs) as signal sources, a dataacquisition system, and signal processing algorithms that enable real-time measurement. The AMI will acquire the first-ever acoustic baseline signature of the ATR.

\section{A. Advanced Test Reactor}

A brief summary of the ATR is presented here. The ATR, a Nuclear Science User Facilities partner, is a versatile reactor for conducting nuclear-physics, reactor-fuel, and structural-material-irradiation experiments [8]. The ATR's maximum power rating is 
$250 \mathrm{MW}_{\text {th }}$ with a maximum unperturbed thermal neutron flux of $1 \times 10^{15} \mathrm{n} / \mathrm{cm}^{2}-\mathrm{s}$ and a maximum fast neutron flux of $5 \times 10^{14} \mathrm{n} / \mathrm{cm}^{2}-\mathrm{s}$. The ATR is cooled by pressurized (2.7 $\mathrm{MPa} / 390 \mathrm{psig})$ water that enters the reactor vessel bottom at an average temperature of $52^{\circ} \mathrm{C}\left(125^{\circ} \mathrm{F}\right)$, flows up outside cylinder tanks that support and contain the core, passes through concentric thermal shields into the open part of the vessel, and then flows down through the core at a temperature of $71^{\circ} \mathrm{C}\left(160^{\circ} \mathrm{F}\right)$ to a flow distribution tank below the core. PCPs situated outside the reactor vessel circulate the water entering the ATR. At least two PCPs are operating along with one emergency cooling pump during reactor operation.

\section{B. Acoustic Receivers}

The acoustic sources selected for use in this research are the periodic pulses originating from a rotating shaft of the five-vane PCPs. The frequency harmonics generated by the pump vanes are nearly identical to signals that would be generated by acoustically telemetered sensors, such as thermoacoustic sensors [4], when inserted into the reactor core. Therefore, periodic pulses from a PCP make an excellent "virtual" acoustically telemetered signal and are utilized for developing ATR acoustic baseline signatures.

Five piezoelectric accelerometers [9], as shown in Figure 1, with a sensitivity of $100 \mathrm{mV} / \mathrm{g}$ and operating frequency of 1 to $17 \mathrm{kHz}$ were installed on the reactor pressure vessel, flanges, and hydraulic shuttle irradiation system (HSIS) in the ATR nozzle trench area to receive the acoustic signals. The average radiation level in the ATR nozzle trench area during reactor operation is $0.165 \mathrm{R} / \mathrm{hr}$. This radiation level had no impact on installed piezoelectric accelerometers and other electronics. The accelerometers were 
installed in June 2015 and to date are functioning as expected. The accelerometers have performed reliably for four ATR normal operation cycles and one power axial locator mechanism cycle. The acoustic signals are routed to a National Instruments Compact Data Acquisition System 9205 [10]. The data are collected at $20 \mathrm{kHz}$. The vane frequency of the PCPs is $148.3 \pm 0.05 \mathrm{~Hz}$.

\section{C. Signal Processing}

The sinusoidal signals generated by PCP vanes are processed to extract frequency, amplitude, and phase information. Figure 2 shows the fast Fourier transformation of the signal time series. In Figure 2, observe that a peak at $148.3 \mathrm{~Hz}$ and associated harmonics are clearly visible at all the sensor locations, thereby ensuring a high signal-to-noise ratio and confirming the use of vane frequency as a virtual acoustically telemetered sensor.

In addition, the Fourier transform is recursively applied to provide information regarding the process states of the ATR. When a single PCP is operated (M6 or M8), the white noise produced by the pumps shade the frequency space (labeled as M6 running and M8 running in Figure 3). When two PCPs are running, the amplitude modulation caused by the interference between two pump frequencies close to $148.3 \mathrm{~Hz}$ becomes apparent and is observed as the bold white line starting at 2016-02-03-18-35-35 in Figure 3. In addition, as observed in Figure 3, (1) the synchronization of the pumps is not stable, because the frequency can be seen to fluctuate from 0.025 to $0.03 \mathrm{~Hz}$ in a periodic manner, and (2) a spike is generated by broadband noise as the M6 pump is turned on with M8 running at 2016-02-03-18-36-35.

Figure 4(a) shows significant variation (sharp changes in frequency) that is attributed to dynamic process states of the ATR when both pumps are operating. One of 
the salient ATR processes that has been detected is the reactor going critical (verified with the ATR operator logbook) on February 02, 2016, as shown in Figure 4(b). Observe how the modulation frequency and amplitude change as the reactor approaches criticality. Similarly, in Figure 4(c), the modulation frequency transitions from a monostable state to a bistable state as the reactor shutdown process is initiated. The AMI outside of the pressure vessel is able to make high-fidelity measurements despite multiple coolant inlets and outlets as well as dynamic fluid flow over structures in the reactor.

\section{III.Conclusion and Path Forward}

Through the AMI installed at the ATR, the first-ever acoustic baseline signature of the ATR was generated by taking advantage of the frequency harmonics generated by the pump vanes. The acquired signatures will enable the effective design of acoustically telemetered sensors. The application of AMI to structural health monitoring has been recognized. In addition, the pump signatures capture the dynamic process states of the ATR. The AMI lays the foundation for real-time, acoustic-based telemetry and in-pile monitoring. Ongoing research efforts are focusing on automating the processing capability to monitor acoustically telemetered signals and detect issues inside the reactor during operation.

\section{Acknowledgements}

The authors would thank Mr. James Lee for his technical support with the dataacquisition system and Mr. Joshua Hrisko for the initial algorithm development.

\section{References}

1. J. L. REMPE et al., "Enhanced In-Pile Instrumentation at the Advanced Test Reactor," IEEE. T. Nucl. Science, 59, 4, 1214 (2012). 
2. B. T. PHAM et al., "Improving Thermal Model Prediction Through Statistical Analysis of Irradiation and Post-Irradiation Data from AGR Experiments," Nuc. Eng. Des., 271, 209 (2014).

3. R. A. ALI et al., "Thermoacoustic Thermometry for Nuclear Reactor Monitoring," IEEE. Instr. Meas. Magazine, 16, 3, 18 (2013).

4. S. L. GARRETT et al., "Fission-Powered In-Core Thermoacoustic Sensor," Appl. Phys. Letters, 108, 144102 (2016).

5. M. FATEMI and J. F. GREENLEAF, "Ultrasound-Simulated Vibro-Acoustic Spectroscopy," Science, 280, 5360, 82 (1998).

6. Nuclear Science User Facilities: http://atrnsuf.inl.gov.

7. N. E. WOOLSTENHULME, “AFIP-6 MKII First Cycle Report,” INL/EXT-1225170, Idaho National Laboratory (September 2012).

8. "FY2009 Advanced Test Reactor National Scientific User Facilities User's Guide," INL/EXT-07-13577, Idaho National Laboratory (September 2008)

9. PCB Piezotronics: http://www.pcb.com/products.aspx?m=355B04.

10. National Instruments NI 9205: http://sine.ni.com/nips/cds/view/p/lang/en/nid/208800. 


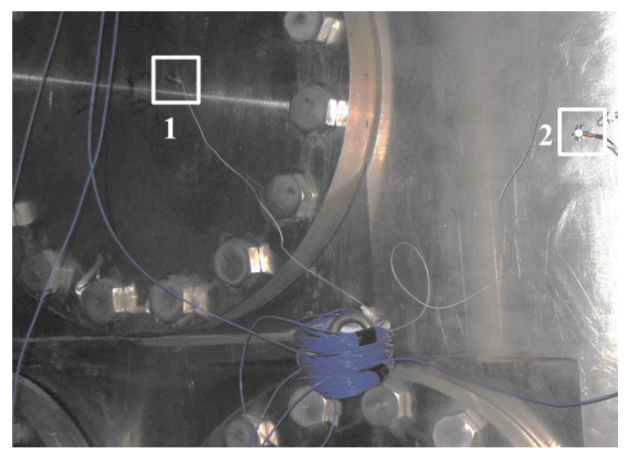

(a)

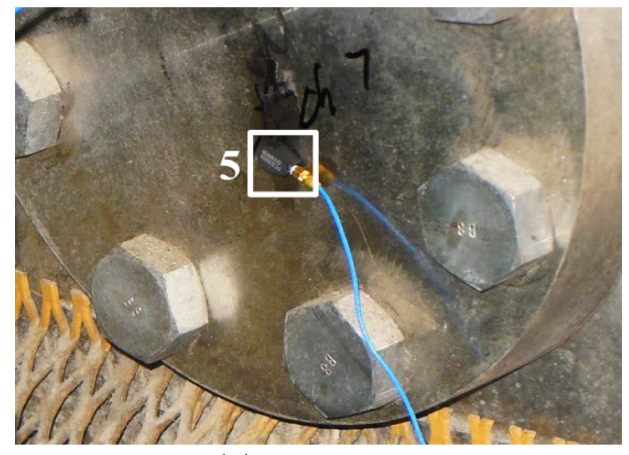

(c)

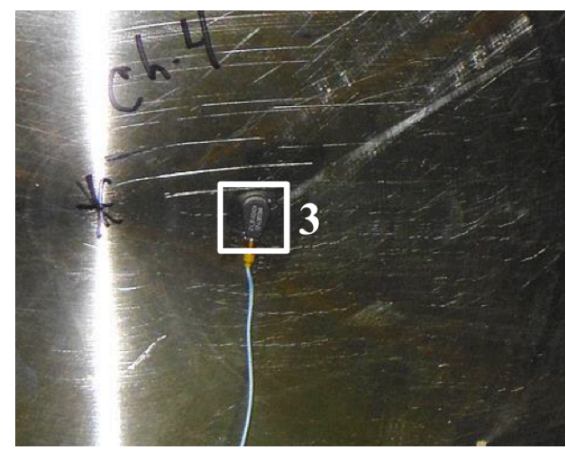

(b)

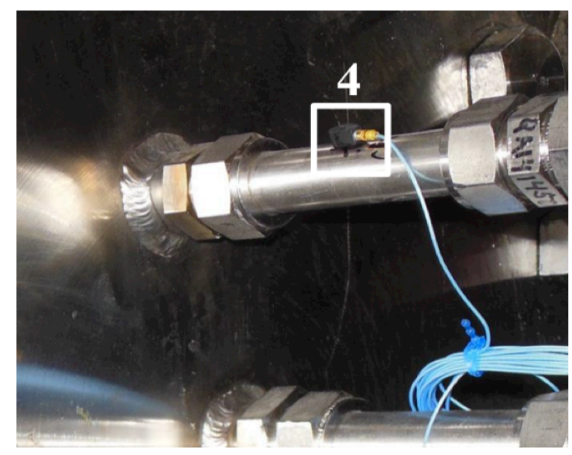

(d)

Figure 1. Piezoelectric accelerometers (acoustic receivers) installed in the nozzle trench area of the ATR. Receiver Location 1 corresponds to the L2 flange, Receiver Location 2 corresponds to the pressure vessel, Receiver Location 3 corresponds to the L7 flange, Receiver Location 4 corresponds to the hydraulic shuttle irradiation system, and Receiver Location 5 corresponds to the $\mathrm{C} 13$ flange. 

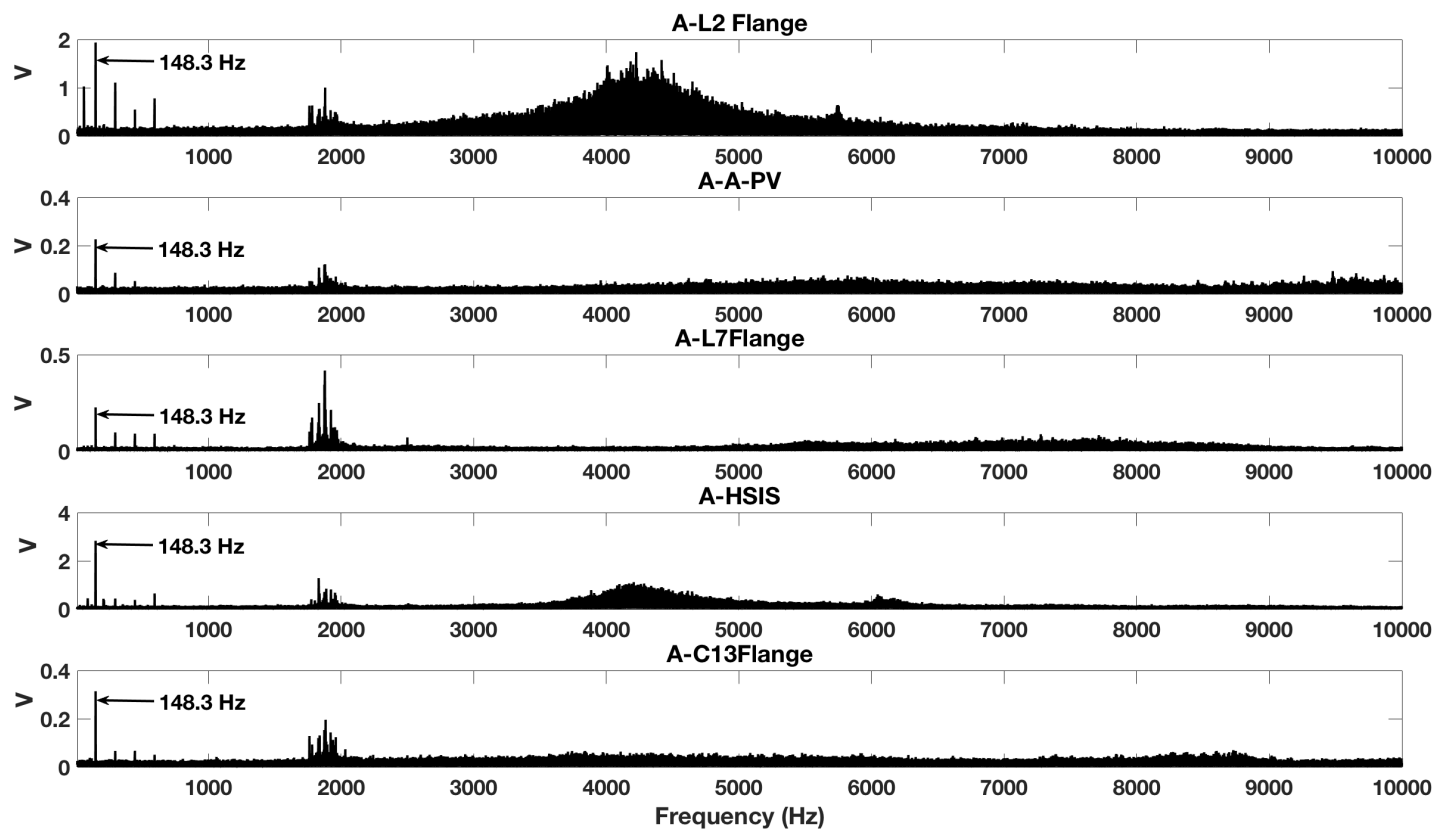

Figure 2. Frequency spectrum of acoustical signals recorded by five piezoelectric sensors installed in the ATR nozzle trench area. The pump vane frequency and its harmonics are clearly observed in the frequency spectrum. 


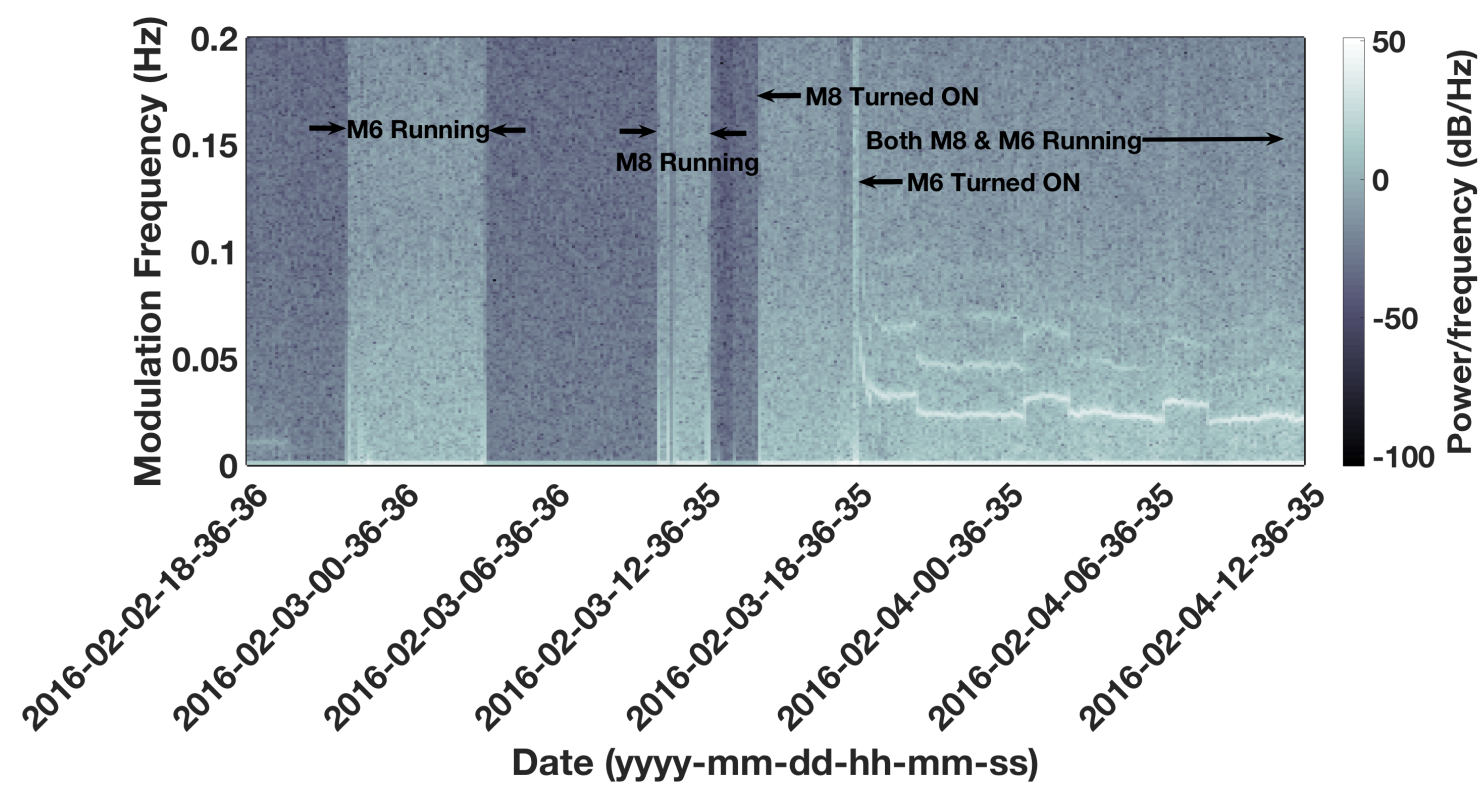

Figure 3. Increase in noise level when PCP M6 and M8 are running individually (see label regions). Amplitude modulation is caused by the interference between two pump frequencies close to $148.3 \mathrm{~Hz}$ when both PCPs are turned ON (bold white line starting at 2016-02-03-18-35-35). Observe fluctuations between 0.02 and $0.03 \mathrm{~Hz}$ indicating synchronization is not stable. 


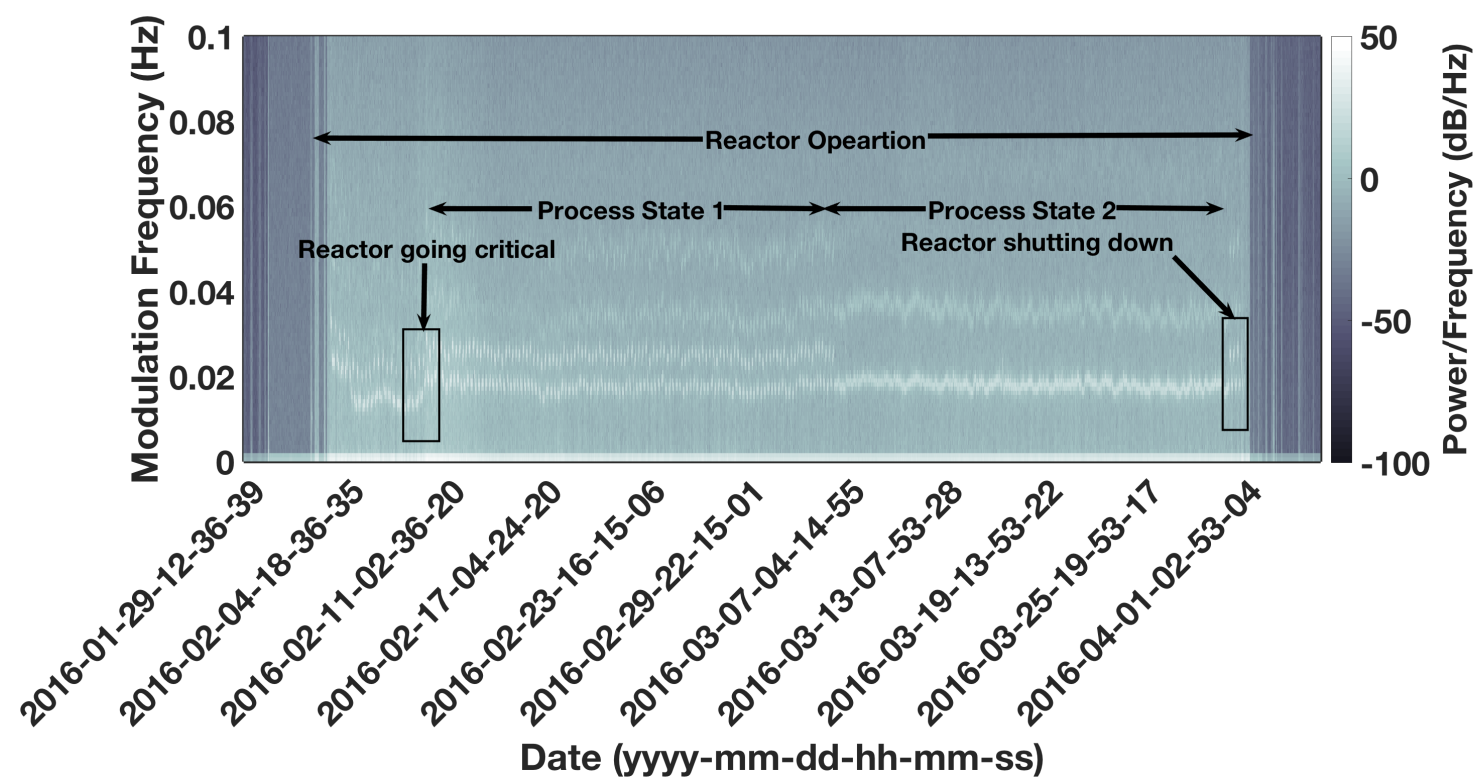

Figure 4(a). Acoustic baseline signature of ATR collected during reactor operation using the AMI. The reactor going critical, Process States 1 and 2, and the reactor shutting down are captured. 


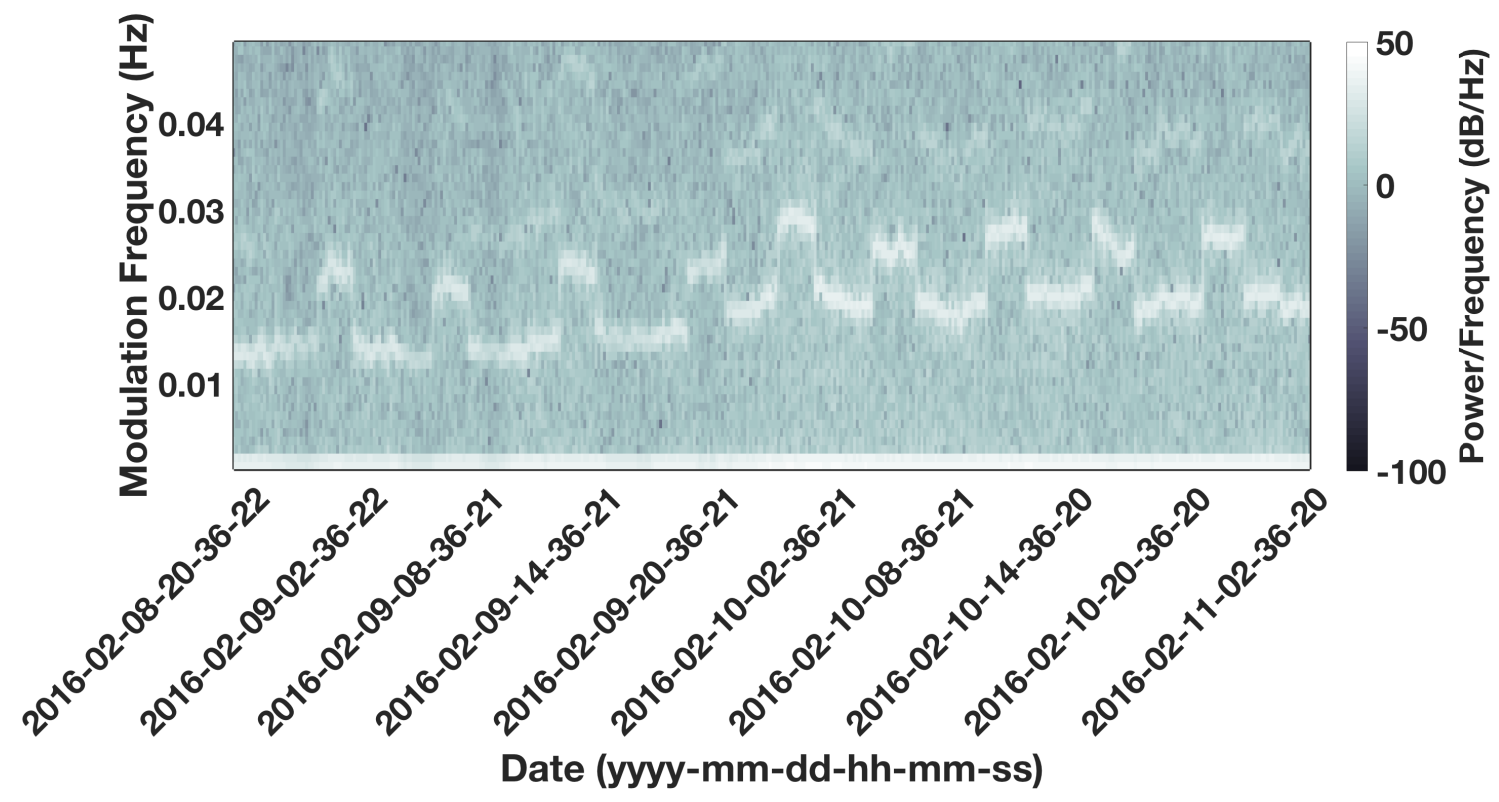

Figure 4(b). Zoomed-in view of the ATR acoustic baseline signature showing shift in the modulation frequency as the reactor approaches and achieves criticality. 


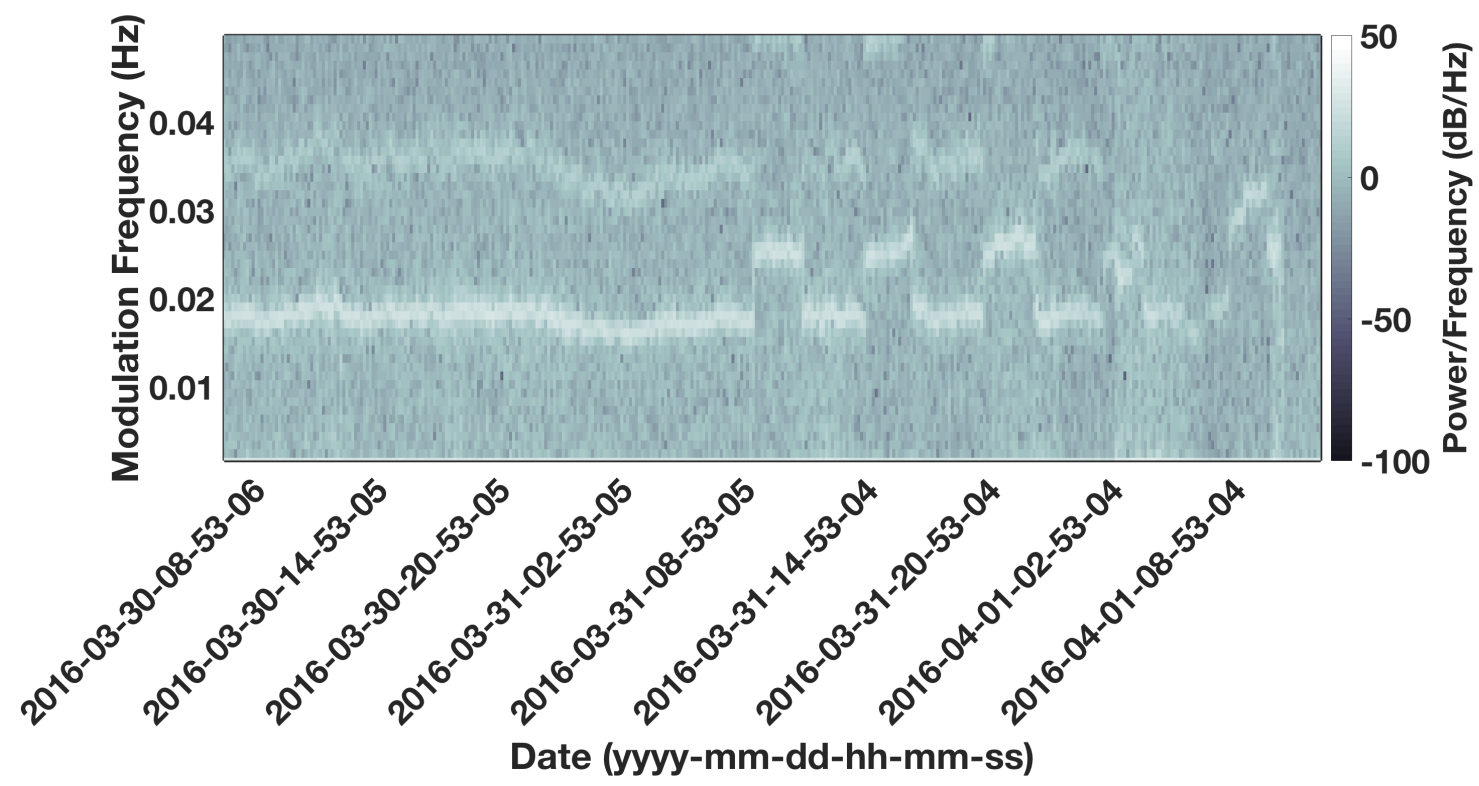

Figure 4(c). Zoomed-in view of the ATR acoustic baseline signature showing variations in the modulation frequency before reactor shutdown. Observe the transition from a monostable state to bistate states. 